\title{
LOGISTICS SENSITIVITY OF CONSTRUCTION PROCESSES
}

\author{
Julia K. Voigtmann \\ Hans-Joachim Bargstädt \\ Bauhaus-Universität Weimar \\ Professur Baubetrieb und Bauverfahren \\ Marienstraße 7a \\ Weimar, 99423, GERMANY
}

\begin{abstract}
Influence parameters on construction processes and logistics are very diverse. Using a simulation model, many parameter variations can be created by taking different input data. Still it is impossible for all process parameters to be taken into account, as their many interrelations form a highly complex system. The lack of time, personnel, and computing capacities hinder the analysis of the whole and complex system. The close relation between construction processes and logistics results in several key parameters being taken into consideration. Identifying which parameters have a smaller and which have a greater impact is relevant in order to develop well performing simulation models and to reduce simulation effort. According to the performed simulation studies, it can be shown, which parameters have to be taken into account, while other parameters can be neglected. The presented research focuses on the sensitivity analysis on the impact of logistics parameters on the simulation results.
\end{abstract}

\section{INTRODUCTION}

In recent years, simulation has been used as a challenging and new approach in the field of construction. Research focuses on different aspects of construction simulation. Given examples are execution planning (Beißert 2011), workspace management (Elmahdi et al. 2011), scenario planning (AbouRizk 2011) and construction site safety (Zhang et al. 2011). Simulated processes vary from infrastructure projects, e.g., roads (Günthner 2010), airports (Scherer et al. 2011) or tunneling (AbouRizk 2011) to structural engineering (Scherer et al. 2011) and outfitting (Beißert 2011).

Due to the nature of the simulation model, several changes of the input and output data can be analyzed. Still it is impossible for all construction process parameters to be taken into account, as their many interrelations form a highly complex system. The lack of time, personnel, and computing capacities hinder the analysis of the whole and complex systems.

One way to solve this problem is to reduce the simulation model to a simplified basis. This implies that special knowledge about the relationship between the input and output data is necessary. And such a reduced model is no more universal. It is only applicable for the one and only special aspect for which it has been generated.

Franz (1989) however postulates that simulation models for construction processes must be very flexible and reactive. This enables the user to consider the characteristics of the construction site as well as of the construction processes. Furthermore the close relation between construction and logistic processes (Voigtmann and Bargstädt 2010) anticipates the inappropriate suppression of parameters which should be taken into account. Especially in outfitting processes a huge variety of construction and logistic strategies must be taken into account.

At the beginning the effects of different application settings, e.g., map scale, routing algorithm, storage search (starting point and direction inside a storage area) on the construction process are largely unspecified. Identifying which parameters have small and which have great impact is relevant in order to develop well performing simulation models.

Depending on the simulation focus the considered parameters (from process, from logistics and model-inherent) have to be thoroughly chosen. Therefore special knowledge about the relationships between the input and output data is necessary. 
The benefits of this detailed knowledge can be illustrated by a simple example. If the quantity of the required heavy construction material is known, the maximum load of the builder's hoist must be taken into consideration. This influence on simulation results is only taken into account in processes which require material defined by its weight. Simulation of processes which are driven by the volume of the material are independent from the hoist's maximum load. On the other hand, for the voluminous material it is a difference, whether construction hoists or cranes are available. Also the effects of several hoists, possibly at different locations, must be analyzed.

Furthermore the effects of changes of input data on the output have to be analyzed. Doubling an input parameter might cause a variation of the output parameter of only a few percent. Then largescale changes of the input parameter are possible without real effect on the output. If, however, a minimal input variation causes large changes in the output, it is necessary to regard this input data in more detail and deliberately use it for changes. So the sensitivity of the whole system is considered regarding the different parameters.

The research focuses on sensitivity analysis between logistics and the construction processes. The paper is structured as follows: First, a short summary of the simulation of construction logistics and sensitivity analyses is given (Section 2). Then an explanation of parameter complexity is outlined (Section 3). Section 4 shows the exemplary analysis of logistic parameters. Finally a summary is included.

\section{SIMULATION OF CONSTRUCTION LOGISTICS}

\subsection{Simulation Model}

The presented approach starts out from a simulation model, which is appropriate to display construction processes, especially outfitting processes. The constraint-based model has been developed by König et al. to analyse construction processes and work orders (König et al. 2007a; König et al. 2007b) The concept is, that work steps can only start, when certain necessary constraints are fulfilled. The model is implemented into the Simulation Toolkit Shipbuilding (STS) of the SimCoMar community (Steinhauer 2007; SimCoMar 2012) and runs on Tecnomatix Plant Simulation (Siemens PLM Software 2012).

Constraints, which must be fulfilled in order to start a work step, are: pre-processes have to be finished and the required material, resources and work area have to be available. This is managed by several STS-components: material control, resource control and constraint manager. Material transports and, if necessary, the rearrangement of stored material are managed by a logistic control component. A detailed description of the program operating mode is given by Voigtmann and Bargstädt (2010).

\subsection{Variable Parameters}

Generally every input data can be described either as a variable or as a boundary condition or as a fixed value. Decisions on how to describe the data depends on the simulation or research focus. Variable parameters inside the simulation model can be clustered into three groups: process-oriented, logistics-oriented and concerning the mode of simulation.

Process-oriented are all parameters, which have influence on the type of construction processes, work order, amount of work, duration and similar, Table 1.

Table 1: Examples for process-oriented parameters

\begin{tabular}{|l|l|}
\hline \multicolumn{1}{|c|}{ Influence on construction process } & \multicolumn{1}{|c|}{ Example } \\
\hline by type & $\begin{array}{l}\text { building type, scope of performances, construction } \\
\text { activities }\end{array}$ \\
\hline by work order & execution schedule, work order, constraints \\
\hline by amount and duration & $\begin{array}{l}\text { scope of work, number of workers, worker } \\
\text { qualification }\end{array}$ \\
\hline others & number of floors, floor plan \\
\hline
\end{tabular}

Logistics-oriented parameters (direct logistic parameters) can be grouped into configurational and strategic parameters. Examples for configurationally parameters are the number and location of hoists 
Voigtmann and Bargstädt

and their capacity and speed, the number, size and location of storage areas and other logistic hardware parameters. Strategic parameters describe logistic strategies, e.g., for delivery or storage, and organizational structures, e.g., responsibilities for several logistic activities. Furthermore beyond these direct logistic parameters there are other parameters which influence the construction site logistics, called indirect logistic parameters. Typical examples are material transport characteristics as dimensions, weights, stackability, or special process characteristics like work area, safety zone, accessibility after work, temporarily or completely blocked areas and areas closed for storage).

The third group of variable parameters are those concerning the mode of simulation. This sum up all model settings, which influence the simulation run, like search algorithms and optimization routines. Map scale and routing algorithms are typical model settings. Furthermore the order of entries in a list (of user defined input data) can result in different settings for the simulation. Entries, which are not prioritised or sorted within a list, are normally processed in their order of entry. For example: two deliveries planned at the same time will be regarded in their order of entry in the list.

The process-oriented and the logistics-oriented parameters are the important input data. In order to analyze and optimize a construction schedule all of the influencing parameters should be varied step by step. To find an optimal parameter combination for the schedule all results have to be compared. Additionally the effects of the model settings have to be considered. The parameters influencing the modes of simulation should have no effects, but it has to be checked thoroughly.

\subsection{Sensitivity Analysis}

Sensitivity analysis investigates the impact on model output changing by varied input parameter. Factor screening is one important part of sensitivity analysis. It analyzes the quantitative influence of input parameters on a result. Local and global sensitivity analyses are the two other parts. They analyze the influence by input parameter variation intra-sectorially or within their general domain (Siebertz et al. 2011).

Sensitivity analysis enables to answer question like: How do the optimal results change when changing input parameters? How inaccurate is a result by using rough input data? Additionally the identification of influencing parameters allows to assess the robustness of a simulation result. Therefore sensitivity analysis is appropriate to analyze sensitivity of the whole system and to identify parameters which have to be thoroughly chosen and which ones are negligible.

Starting point is the above mentioned factor screening. Factors with obvious impact have to analyzed in more detail. Choice between local and global sensitivity analysis is based on factor properties and factor reflecting. With the scope of the application in mind, some factors are analyzed in realistic ranges only. For example it is not necessary to vary packaging size parameter from zero to infinity.

\section{PARAMETER COMPLEXITY}

The number of possible variable parameters is almost innumerable. Furthermore the range of each parameter can be limited to technical or local conditions, e.g., hoist's capacity or size of storage areas. For example for analyze hoist's capacity also the size of the increments of the parameter is restricted.

For other parameters the valid range of values or parameter increments is not really known. Often ranges of value are defined by experience or careful consideration. More difficult it is to define the appropriate parameter increments. The increment might be constant, exponential or freely selectable.

The following example shows the complexity of the problem. In a large office building one single outfitting trade in the $8^{\text {th }}$ floor is considered. Assume that four types of builder's hoists (different in speed and capacity) and three possible locations are available. Furthermore a minimum of two workers and a maximum of five is given. All assumed site conditions (parameters) are given in Table 2, the suitable range of parameter values is also shown. 
Table 2: Parameters and values for an exemplary site

\begin{tabular}{|l|l|l|}
\hline Parameter & Suitable parameter values & $\begin{array}{c}\text { Number of } \\
\text { values }\end{array}$ \\
\hline type of builder's hoist & type A, type B, type C, type D & 4 \\
\hline $\begin{array}{l}\text { location of builder's } \\
\text { hoist }\end{array}$ & location A, location B, location C & 3 \\
\hline number of workers & $2,3,4,5$ & 4 \\
\hline delivery strategies & "all at the beginning", "daily", "weekly" & 3 \\
\hline packaging size & $25,30,35$ per pallet & 3 \\
\hline storage strategy & central $(4$ possible locations), distributed on each floor & 5 \\
\hline storage size & from $10 \mathrm{~m}^{2}$ to $40 \mathrm{~m}^{2}$ with increments of 5 $\mathrm{m}^{2}$ & 7 \\
\hline $\begin{array}{l}\text { responsibility for } \\
\text { logistic activities }\end{array}$ & $\begin{array}{l}\text { "all work done by workers", "workers only assemble", } \\
\text { "unloading and storage by logisticians" }\end{array}$ & 3 \\
\hline work order & upstream, downstream & 2 \\
\hline
\end{tabular}

The parameter list can easily be extended. To find the optimal combination of these parameters, every parameter value must be combined with each other. Already this small example yields more than 90.000 possible combinations, which is the product of all numbers of values. Effects of the model settings (e.g., map scale, increment size) are still not regarded.

Assuming, that an optimal combination has been found and realized and that the company gets a similar contract with the same kind of work, the same building type, a similar ground floor plan and same other conditions. But that building has only 4 floors instead of 8 . Theoretically all parameter combinations have to be analysed again. If one single simulation run including parameter setting and documentation of the values and the results takes 5 minutes, then analysing all 90.000 combinations needs more than 300 days.

It is obvious that a concentration on the most governing parameters is necessary. With respect to the engineering logic some parameter correlations are obvious. For a two storey building it is not necessary to vary the hoist's speed or capacity. There the efforts for vertical transport in comparison to horizontal transport are negligible. Also for distributed storage areas the range of values for the size of storage areas is less crucial than for central storage. The maximum number of workers is limited by the demand on work space. These are examples for obvious correlations, but often parameter correlations are not so obvious and easy to be identified.

Engineering and logistic knowledge about the major parameters of influence is essential. To accelerate planning, irrelevant parameters and parameter combinations should be eliminated. It minimizes experimental scheduling and the number of simulation runs. The identification of typically qualified parameter combinations, which depend on specific processes or building attributes, ensures optimisation potential and makes it quickly accessible. Especially the influence of logistic parameters on construction processes is not much explored yet (Voigtmann and Bargstädt 2010).

\section{LOGISTIC SENSITIVITY}

If doubling an input parameter causes only a variation of the output parameter by a few percent, then large-scale changes of this input parameter becomes possible. Otherwise, if a minimal change in input causes big changes in output parameter variety, it is necessary to regard this input data in more detail and change it very carefully. Analyzing such system reactions and effects of changes of single input data on the other parameters shows the sensitivity of the model.

In the following this sensitivity analysis is shown on the logistics in the model. It shows the exemplary analysis of direct and indirect logistic parameters on other processes and the application of these on different ranges of parameter values.

\subsection{Size of Storage Area}

Construction processes are affiliated to logistic processes. Deliver of material and transport to location of installation are preconditions for assembling. Material flow is often disturbed by interlaying and other temporary obstacles. Processes for material transport, storage and rearrangement sums up to ca. 15 percent of daily working time (Boenert and Blömeke 2006). Further 15 percent are caused by ways 
(between working and storage areas et al.). Boenert and Blömeke (2006) identify a high optimization potential by choosing a suitable storage strategy, which includes storage area size and location as well.

Contrary to the stationary industry the storage area sizing problem cannot be solved by static evaluation. On construction sites the available areas change permanently and are used for assembling and storing alternating or contemporarily. Stored material outside defined storage areas obstructs the construction process. Therefore construction processes are delayed. That induces changing conditions for the storage area sizing problem. Tailback areas outside the original storage area prevent such problems in warehousing. On construction sites this is unusual and not possible (e.g., outfitting material cannot be stored outside the building). Furthermore solutions for the problem of storage area sizing in stationary production are based on steady and predictable production processes with defined input factors. Construction processes are influenced by highly variable and partially non-predictable parameters.

For one single trade (experiment 1), a defined scope of work and work order is given. The size of the storage area is varied. Starting from a room-wide and $0.5 \mathrm{~m}$ long storage area as a central storage on ground floor, this area is incremented in the following simulation run by $0.5 \mathrm{~m}$. The maximum storage width is the length of building wing. The number of simulations is 50 . For all these runs the construction time and different logistic time demands are recorded.

The chosen strategy for material delivery is to deliver all material at the beginning. If the central storage area is full, the surplus material will be stored near its point of demand. This means that in case of a small central storage size the material is more often stored near the point of demand. Consequently it might be assumed, that the paths for material transport might be shorter and therefore the construction might be faster too.

This assumption seems to be true in general, Figure 1. But obviously there seems to be an oscillation in the picture, which needs to be explained. Therefore the value tendency is marked over the ground floor plan (Figure 2), and the material storage processes is analyzed in more detail.

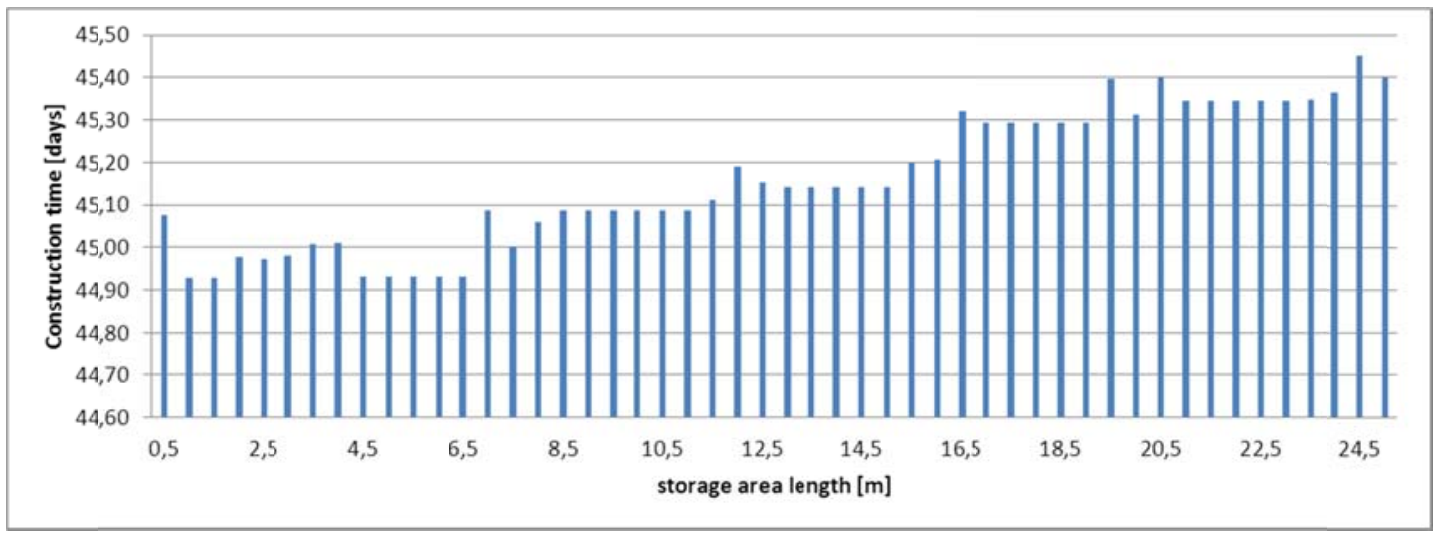

Figure 1: Construction time (experiment 1) 


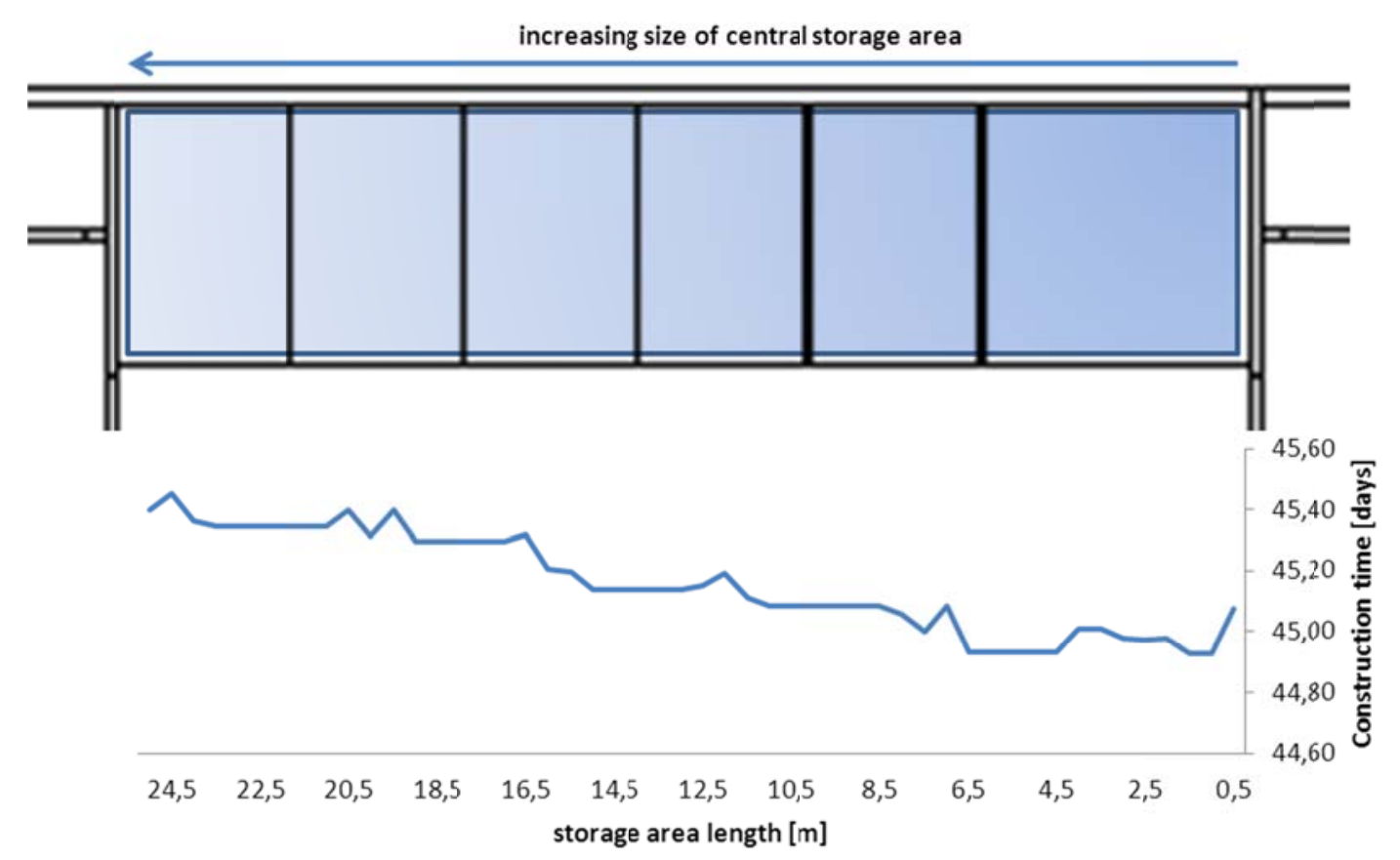

Figure 2: Contrasting ground floor plan versus size of storage area and construction time

The variation of the values can be explained by the presetting storage search, which is part of the model setting. Areas are represented in the simulation model by a regular grid. A grid element can be occupied or not, but it cannot be partly occupied. The storage need for one material is now rounded up to one or more grid elements. The search algorithm for storage always starts in the lower left corner, and the search direction is upstream. The used algorithm does not optimize the stored material within the area. The problem is illustrated in Figure 3.

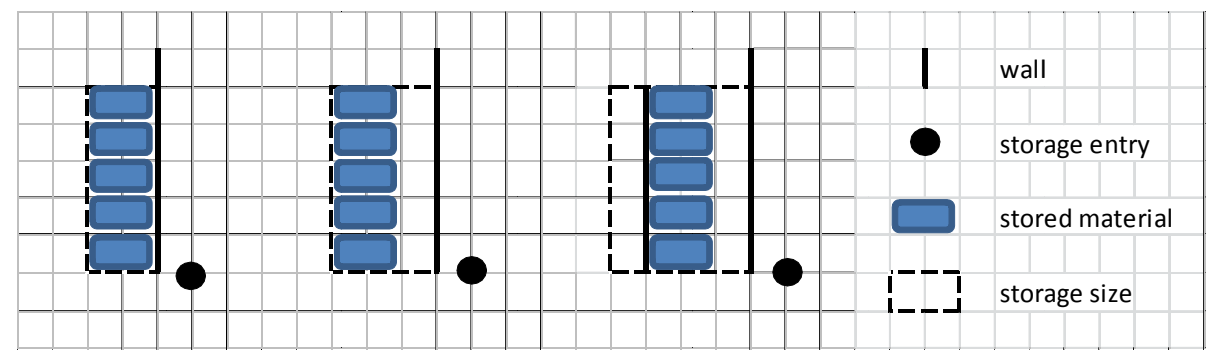

Figure 3: Schematic functionality of search algorithm for storage

Depending on the distance from the left storage border to a wall and on the material size, the available areas are used very differently. In some cases the total number of stored material decreases, if the storage size is increased.

General the total number of stored material increases, if the storage size is increased. The amount of material which is stored near the point of demand decreases. Additionally the material inside the storage area is located far away from the storage entry. Finally the construction time rises. It is noted that the maximum central storage size cannot keep all material at the same time.

If material is stored near a wall (i.e., the left storage border is near a wall), additional rearrangement activities are necessary, for example because of work areas in front of the wall which have to be cleaned later. The material is brought near to the point of demand. Therefore the effort for material transport to the assembling point is reduced. In the experiment 1 the additional rearrangement activities are smaller according to the saved time for material transport to the assembling point. Hence the construction time for simulation runs with storage boarders near walls is shorter (see Figure 2). 
To reduce the stored material another delivery strategy is chosen in (experiment 2. A single delivery contains only the demand for one story. Hence the required storage size peaks in simulation Nr. 15, Figure 4. All material is now stored inside the storage area. Every additional increase of storage size leads to increasing distances between storage entry and stored material, but that effect is negligible. The shown correlation between the ground floor plan and the storage size, which is affected by the preset storage search algorithm, is still slightly recognizable.

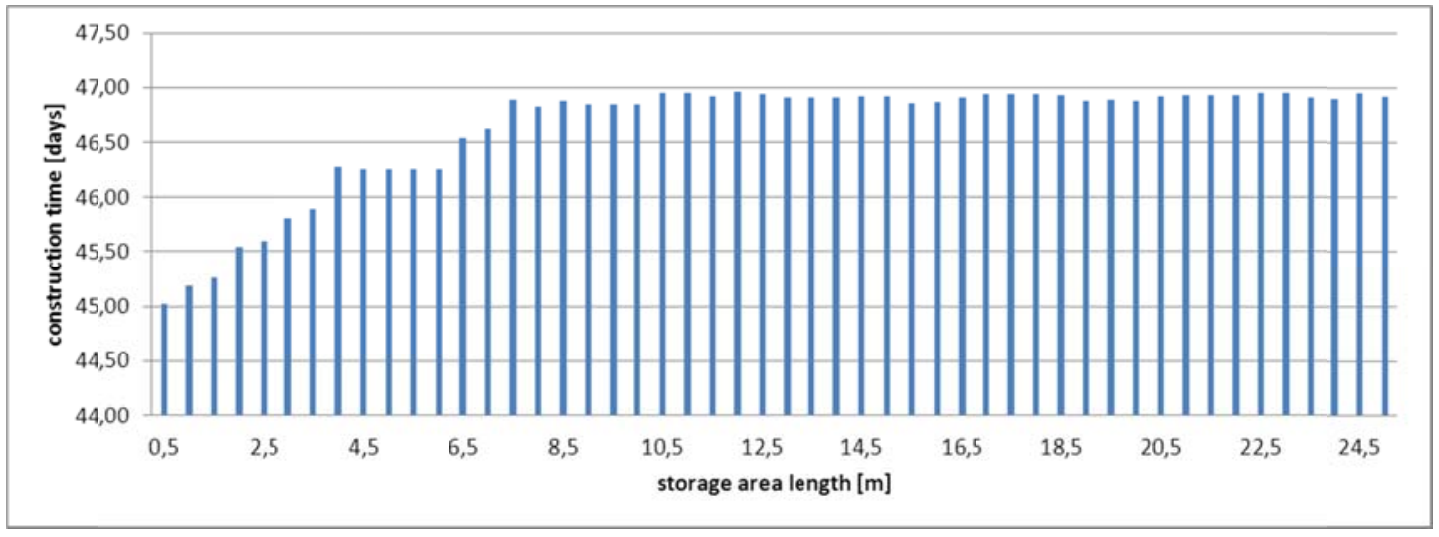

Figure 4: Construction time (experiment 2)

To confirm the impact of the starting point for storage search this point is now fixed to the right border of the storage area, experiment 3 . Material is stored in the same position while increasing the storage size. In the first run the above mentioned effects are visible: rising construction time because of storage in central storage area instead of near the point of demand. Then some special effects occur in the next simulation runs, which mean that the storage is near the point of demand and no additional rearrangement activities are necessary. When the storage size correlates to the maximum need of storage area (Figure 5, simulation run no. 22), there is no further change in construction time.

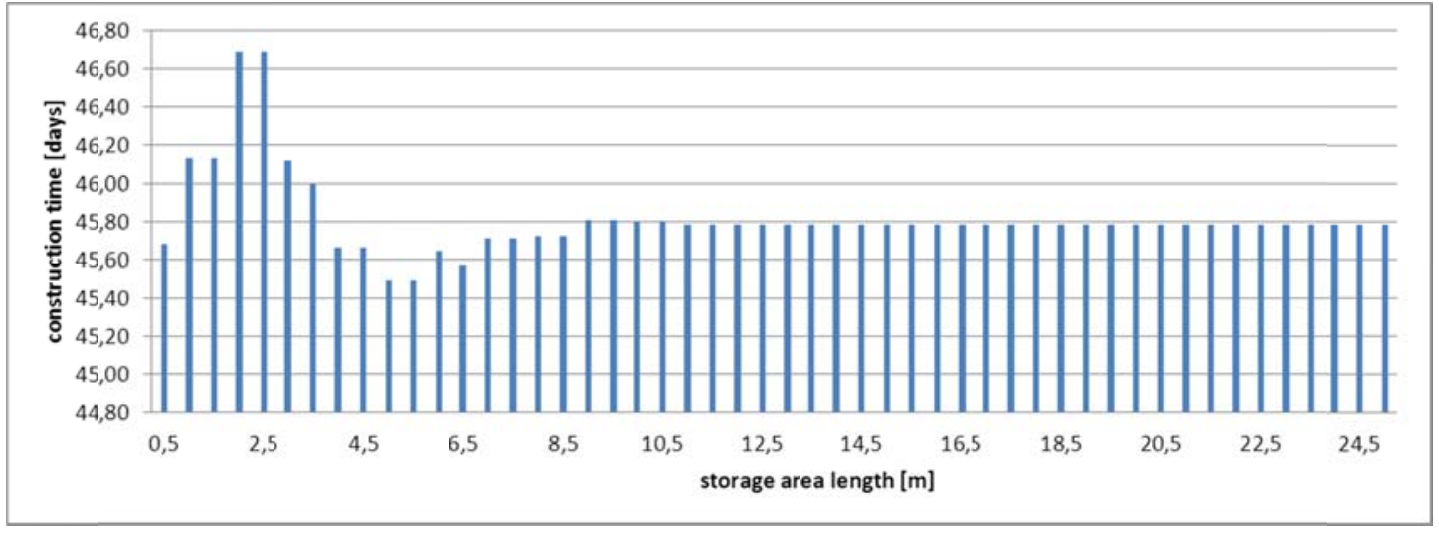

Figure 5: Construction time (experiment 3)

To confirm the impact of the ground floor plan and the wall alignment within the storage area, the experiment 1 has been changed to another ground floor plan, named experiment 4 . The scope of work decreases according to the reduced number of walls. The recorded construction time oscillates similarly to experiment 1 (Figure 6). The further existing oscillation shows in evidence, that still search strategy and material storage dimensions have main influence. According to the chosen scale of grids, an increase in size not automatically causes an increase of the number of stored material, see Figure 3 as well. The preset storage search algorithm leads to no effect on the construction time, if the borders of the storage areas are near front or back walls. This was already obvious from Figure 2. 


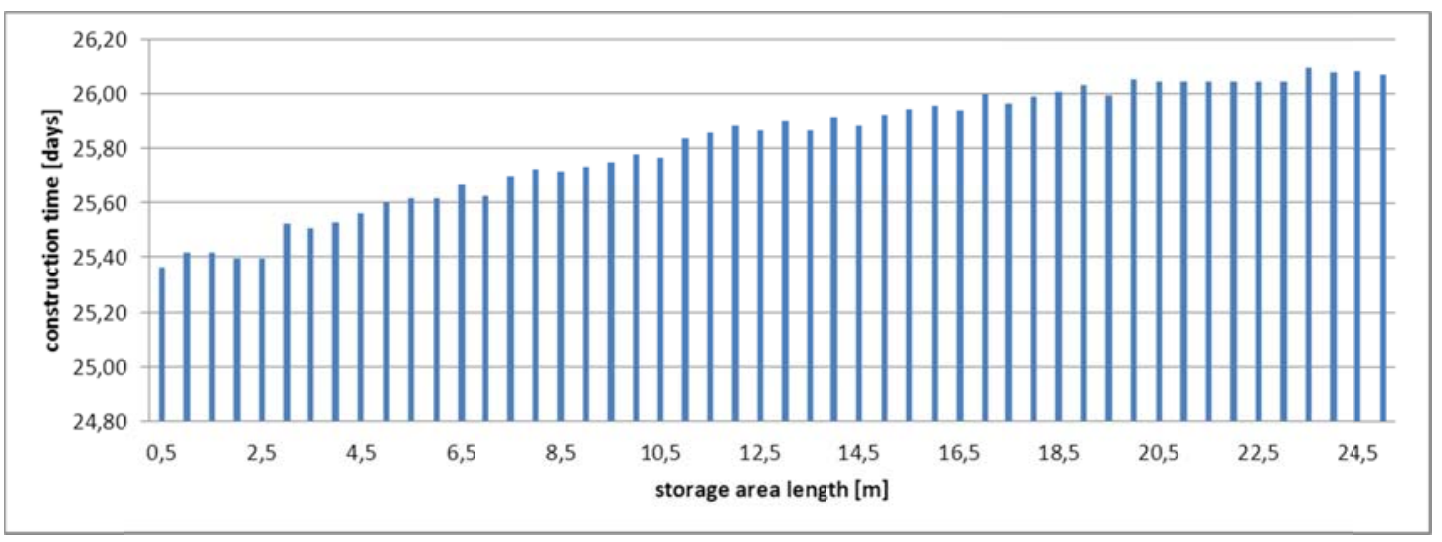

Figure 6: Construction time (experiment 4)

Now, to reduce the number of possible parameter combinations for the optimization of the storage size on construction sites, the following aspects should be considered:

- The increment of increase in the size of the storage area should correspond to the material size and to the map grid.

- Size values which regard to storage borders direct next to the front or back walls should be neglected. There is no improvement in construction time.

- Choose a storage search algorithm and its starting point according to the direction of filling of the storage and the center of the point of demand.

- There is no further storage increase necessary, if the maximum required storage size is reached, which might be estimated in a separate calculation beforehand.

\subsection{Packaging Size}

Another typical variable concerning logistic parameters and its influence on construction time is the packaging size. A changed packaging size changes the number of packages and in the end the required storage area. Additionally fewer packages reduce the number of transports. Because of the close relation between construction and logistic processes and their innumerous and partially nonpredictable influence factors specific differences exist to the stationary industry, see chapter 4.1.

Values for packaging size (for example number of tiles per pallet or package) are defined by the common market and the availability of the product. To analyze the effect of different packaging sizes some other, uncommon values are regarded too. Therefore it is guaranteed, that the other parameters need not to be changed. That means, that for example load capacity and dimensions remain constant, only the stacking high is variable. So other disturbing effects like different transport compositions and changing demands for storage area are excluded.

Four different process types with different material requirements are analyzed: drywall construction (experiment 5), wall papering (experiment 6), ceiling element assembly (experiment 7) and assembling of light switches panel (experiment 8). The amount of tiles and the values for the packaging sizes are shown in Table 3.

Table 3: Amount of tiles, packaging size and number of packages

\begin{tabular}{|r|r|r|r|}
\hline Process type & Amount of tiles & Packaging size & $\begin{array}{c}\text { Responding number of } \\
\text { pallets/packages }\end{array}$ \\
\hline drywall & 4992 & $15 \ldots 38$ & $333 \ldots 132$ \\
\hline $\begin{array}{r}\text { wall } \\
\text { papering }\end{array}$ & 7104 & $12 \ldots 39$ & $592 \ldots 183$ \\
\hline $\begin{array}{r}\text { ceiling } \\
\text { electrical } \\
\text { installation }\end{array}$ & 17152 & $100 \ldots 325$ & $172 \ldots 53$ \\
\hline
\end{tabular}


Altogether ten simulations have been run for each process type. The construction time calculated by the simulation is shown in regard to the increasing packaging size and the decreasing number of packages, Figure 7.
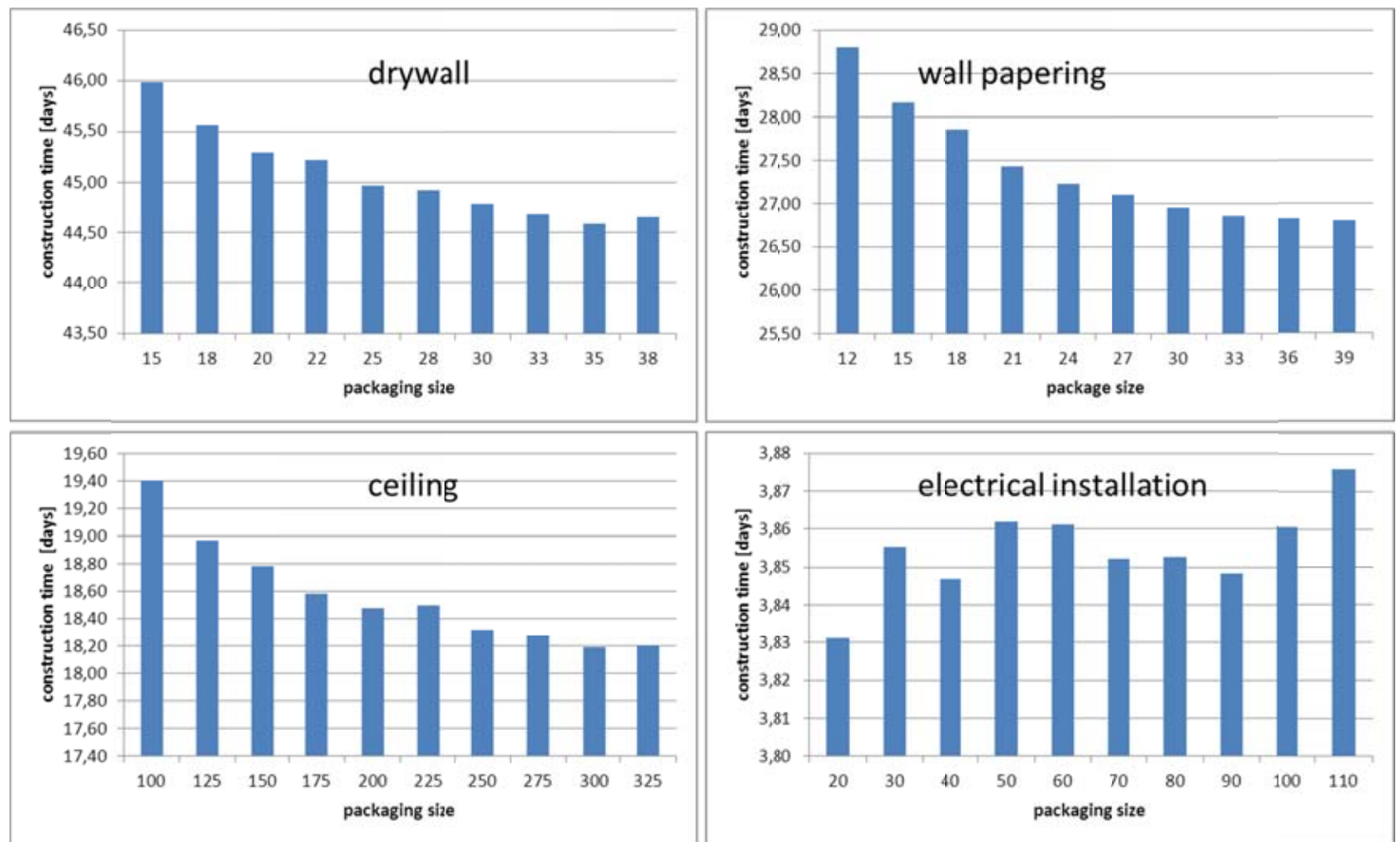

Figure 7: Construction time (experiments 6-9)

In all experiments but the electrical installation the construction time is decreasing with increasing packaging size. This can be explained, because fewer packages have to be unloaded, and hauled into the building, stored and rearranged, if necessary. To analyze the savings in construction time in more detail, each two neighboring packaging sizes are compared to each other. Their maxima of possible time savings are listed in Table 4.

Table 4: Maxima of saved construction time between two neighboring packing sizes

\begin{tabular}{|r|r|r|}
\hline \multicolumn{1}{|c|}{ Process type } & $\begin{array}{c}\text { Maximum of saved } \\
\text { construction time [\%] }\end{array}$ & $\begin{array}{c}\text { Maximum between } \\
\text { run no. }\end{array}$ \\
\hline drywall & $0,9 \%$ & run $1 /$ run 2 \\
\hline wall papering & $2,2 \%$ & run $1 /$ run 2 \\
\hline ceiling & $2,2 \%$ & run $1 /$ run 2 \\
\hline electric installation & $0,2 \%$ & run $5 /$ run 6 \\
\hline
\end{tabular}

To explain the different time savings it helps to respect the assembling time per tile. It varies from 20 minutes for drywall to 8 minutes for wall papering and 2 minutes for ceiling. The higher the ration is between activity duration and transport of packing unit, the more the packaging size influences the overall process.

Next it is supposed that the different behavior in the electrical installation in Figure 7.4 depends on the chosen storage size. Smaller packages decrease the distance between the center of storage of material and the entry to the storage area, as already explained in section 4.1. To verify this hypothesis, the starting point of the storage search is varied and the simulation is run again in experiment 9. Looking on the total of simulation runs, the increasing construction time regarding to the decreasing number of packages is obvious. Only neighbored simulation runs show, that a decrease of packages causes also a decrease of construction time, Figure 8. It is therefore supposed, that the process parameters, which are the assembling time per tile and the overall number of tiles etc., have a high influence in the transport activities during construction in experiment 9. 


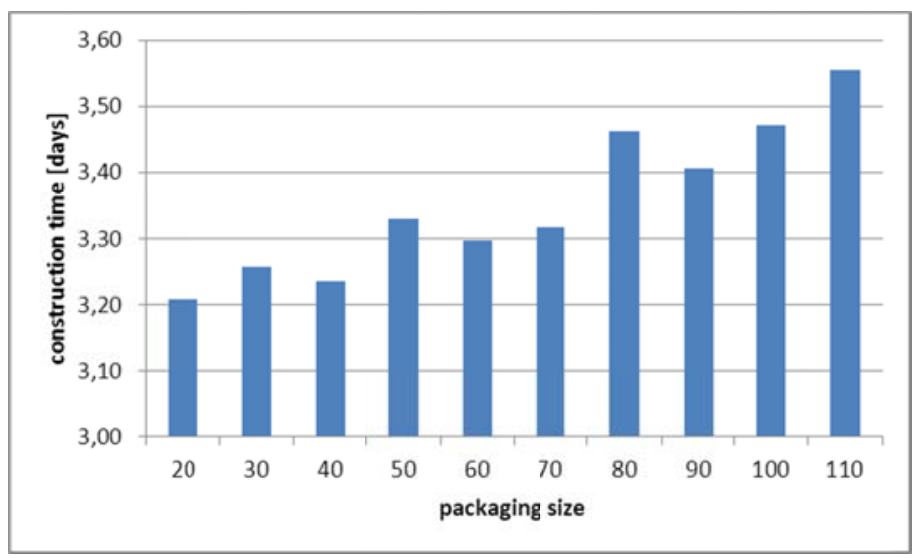

Figure 8: Construction time (experiment 9)

To analyze the influence of the transport activities it is appropriate to compare the different logistic activities. For each simulation run the sum of the duration of all performed simulation for assembling, for material transport and for packaging/handling is recorded. Then the ratio between the sum of the overall assembling time and the overall transport time is calculated and the ratio between assembling and packaging/handling as well, Table 5 .

Table 5: Assembling, material transport and packaging handling time

\begin{tabular}{|r|r|r|r|r|r|}
\hline Process type & Assembling & $\begin{array}{c}\text { Material } \\
\text { transport } \\
\text { [hours] }\end{array}$ & $\begin{array}{c}\text { Packaging } \\
\text { handling } \\
{[\text { hours] }}\end{array}$ & $\begin{array}{c}\text { Assembling } \\
\text { : } \\
\text { Material } \\
\text { transpours] }\end{array}$ & $\begin{array}{c}\text { Assembling } \\
: \\
\text { Packaging } \\
\text { handling }\end{array}$ \\
\hline drywall & 1664,0 & 51,4 & 99,7 & 0,03 & 0,06 \\
\hline $\begin{array}{r}\text { wall } \\
\text { papering }\end{array}$ & 947,2 & 64,8 & 112,0 & 0,07 & 0,12 \\
\hline ceiling & 571,7 & 122,1 & 54,8 & 0,21 & 0,10 \\
\hline $\begin{array}{r}\text { electrical } \\
\text { installation }\end{array}$ & 106,7 & 38,3 & 0,9 & 0,36 & 0,01 \\
\hline
\end{tabular}

Packaging/handling corresponds to the different number of packages, ways, times for lifting and putting down per packaging, which differs because of different weights. It is obvious, that the sum of all logistic activities in electro installation is only governed by the material transport activities. In addition there is a high amount of logistic activities directly attached to the assembling. Hence small variable storage locations, which are possible with decreasing packaging numbers, have a great effect on the construction time. This effect based on the preset storage search. Decreasing packaging numbers increase distance between material inside the storage area and the storage entry. Material transport ways increase and finally the construction time rises.

In summary the following facts should be respected:

- If the proportion of logistics for material transport and packaging/handling is very small in regard to the assembling, then there is no need for being precise in the detailed packaging sizes.

- In processes, which are dominated by the transport of material and the packaging, the packaging size should correspond to construction time.

- To analyze the effect of different packaging sizes in processes, which are dominated by the material transport, the packaging size must be chosen very carefully. To only shift the center of storage areas can have considerable effects in the simulation, which might not be the same in reality. 


\section{SUMMARY}

Influence parameters on construction processes and construction logistic are multiplex. To reduce simulation efforts it is not possible to randomly neglect some of the parameters. The presented paper points out, that some parameters unexpectedly have a great effect on the simulation results, which depends on the simulated process, chosen logistic conditions and the modes of simulation presetting. It also showed, that the influence of a number of other parameters can be neglected, since those have almost no influence on the simulation results.

In summary the general analysis of parameters and their influence allows to focus on the main parameters and their realistic value ranges. The given examples show effects on some typical criteria. Just to better understand the underlying engineering and logistic determinants, other parameters should be analyzed as well, in order to be able to better optimize future simulation models for larger contexts and complex buildings.

\section{REFERENCES}

AbouRizk, S. M. 2011. "A construction synthetic environment integrating visualization and simulation." In: 11th International Conference on Construction Applications of Virtual Reality 2011. Edited by H.-J. Bargstädt and K. Ailland. Weimar, Verlag der Bauhaus-Universität Weimar.

Beißert, U. 2011. Constraint-basierte Simulation zur Terminplanung von Ausführungsprozessen. Weimar, Verlag der Bauhaus-Universität Weimar.

Boenert, L. and Blömeke, M. 2006. Kostensenkung durch ein zentrales Logistikmanagement. In: Baulogistik - Konzepte für eine bessere Ver- und Entsorgung im Bauwesen. Edited by U. Clausen. Dortmund, Verlag Praxiswissen.

Elmahdi, A., Wu, I.-C., and Bargstädt, H.-J. 2011 "4D grid-based simulation framework for facilitating workspace management." In: 11th International Conference on Construction Applications of Virtual Reality 2011. Edited by H.-J. Bargstädt and K. Ailland. Weimar, Verlag der Bauhaus-Universität Weimar.

Franz, V. 1989. Planung und Steuerung komplexer Bauprozesse durch Simulation mit modifizierten höheren Petri-Netzen. Dissertation. Kassel.

Günthner, W. A. 2010. Virtuelle Baustelle - Abschlussbericht 2010. Digitale Werkzeuge für die Bauplanung und -abwicklung. Lehrstuhl für Fördertechnik, Materialfluss, Logistik. Garching.

König, M., Beißert, U., and Bargstädt, H.-J. 2007a. „Constraint-Based Simulation of Outfitting Processes in Ship Building and Civil Engineering". In: 6th EUROSIM Congress on Modelling and Simulation. Edited by B. Zupančič, R. Karba and S. Blažič. Ljubljana. SLOSIM - Slovene Society for Simulation and Modelling.

König, M., Beißert, U., and Bargstädt, H.-J. 2007b. „Visual Simulation - An Appropriate Approach to Support Execution Planning in Building Engineering". In: 7th International Conference on Construction Applications of Virtual Reality. Pennsylvania. Pennsylvania State University.

Scherer, R. J., Tauscher, H., and Schapke, S.-E. 2011. Mefisto: eine Modell-, Informations- und Wissensplattform für das Bauwesen. Tagungsband 2. Mefisto Kongress, 13. Oktober 2011, Dresden. Dresden, Institut für Bauinformatik.

Siebertz, K.; Bebber, D. van and Hochkirchen, T. 2011. Statistische Versuchsplanung. Design of Experiments (DoE). Heidelberg, Springer.

$\begin{array}{lllll}\text { Siemens } & \text { PLM } & \text { Software. } & \text { Accessed } & \text { March }\end{array}$ http://www.plm.automation.siemens.com/en_us/products/tecnomatix/plant_design/plant_simulatio n.shtml.

SimCoMar. 2012. Accessed March 19. http://www.simcomar.com.

Steinhauer, D. 2007. „Simulation im Schiffbau und Kooperation mit der Bauhaus-Universität Weimar." In: 1. IBW Workshop Simulation in der Bauwirtschaft. Edited by V. Franz. Kassel, kassel university press.

Voigtmann, J. K., and Bargstädt, H.-J. 2010. “Construction logistic planning by simulation”. In: 2010 Winter Simulation Conference. Edited by B. Johansson, S. Jain, J. Montoya-Torres, J. Hugan and E. Yücesan. Baltimore.

Zhang, S., Lee, J. K., Venugopal, M., Teizer, J., and Eastman, C. 2011. "Integrating BIM and Safety: An Automated Rule-Based Checking System for Safety Planning and Simulation". IN: Proceedings of the CIB W099. Washington D. C. 


\section{AUTHOR BIOGRAPHIES}

JULIA KATHARINA VOIGTMANN is a civil engineer. After her diploma in Weimar she work at STREIF Baulogistik GmbH, Essen, Germany. Her daily work focussed on construction logistic planning. Four years ago she went back to the university to do her dissertation on the chair of construction engineering and management at the Bauhaus-University in Weimar. She is taking her doctoral degree in Civil and Structural Engineering in the field of process modelling and simulation. The objective of the dissertation is to analyse qualified logistic strategies depending on several process or building attributes by simulation. Therefore she developed a simulation model to simulate logistic activities on site. Her email address is julia.voigtmann@uni-weimar.de.

HANS-JOACHIM BARGSTÄDT is Professor for Construction Engineering and Management at the Bauhaus-University Weimar. He studied in Braunschweig, Atlanta and Marseille. He got his Ph. D. from the Technical University Braunschweig in 1988. He worked 3 years in structural engineering offices. After his Ph. D. he worked more than 10 years for an international construction company. There he was responsible site engineer, site manager and project manager for several projects. As branch manager and director of a branch office he managed many different projects as dry docks, harbor construction and bridges as well as hotel and office buildings, and construction in the built environment. Since 2000 he is Professor at the Bauhaus-University Weimar. His research fields are construction processes, construction management, simulation in construction, construction in the built environment and lifecycle considerations. E-mail is hans-joachim.bargstaedt@uni-weimar.de. 